\title{
Piezoceramic shunted damping concept: testing, modelling and correlation
}

\author{
Gä̈l Chevallier ${ }^{a}$, Salma Ghorbel and Ayech Benjeddou \\ Institut Supérieur de Mécanique de Paris, LISMMA, Structures, 3 rue Fernand Hainault, 93407 Saint-Ouen Cedex, France
}

Received 6 October 2008, Accepted 12 May 2009

\begin{abstract}
New laboratory tests are presented for the experimental evaluation and assessment of the piezoceramic shunted damping (PSD) concept for cantilever Aluminium thin (long) beams bonded symmetrically on their upper/lower surfaces with single pairs of small piezoceramic patches. Following these tests outcome, the PSD efficiency measure is proposed to be the so-called modal effective electromechanical coupling coefficient, which is post-processed from free-vibrations analyses under short-circuit and open-circuit electrodes of the patches. For this purpose, the tests are numerically modelled, analysed, and correlated using ABAQUS ${ }^{\circledR}$ commercial finite element (FE) code. Good tests/models correlations were reached after FE models electromechanical updating. This is attributed to the refined FE models in the sense that they have considered realistic and desirable features such as, electrodes equipotentiality, piezoceramic patches poling orientations (same/opposite), and the corresponding (parallel/series) electric wiring (connections).
\end{abstract}

Key words: Piezoceramic shunted damping / experimental tests / finite element analysis / electrodes equipotentiality / piezoceramic poling orientation / patches electric wiring / models electromechanical updating

\begin{abstract}
Résumé - Concept d'amortissement piézoélectrique shunté : expérimentation, modélisation et corrélation. De nouveaux tests de laboratoire sont présentés pour l'évaluation expérimentale du concept d'amortissement piézocéramique shunté (APS) pour des poutres cantilever minces (longues) en Aluminium sur lesquelles sont collées symétriquement sur leurs surfaces supérieures/inférieures des paires uniques de petits patches piézocéramiques. Suite aux résultats de ces tests, le coefficient de couplage électromécanique effectif modal, obtenu par post-traitement à partir d'analyses vibratoires avec des électrodes de patches en court-circuit et circuit ouvert, est proposé comme mesure de l'efficacité de l'APS. Pour cela, les tests sont numériquement modélisés, analysés et corrélés à l'aide du code commercial d'éléments finis (EF) ABAQUS ${ }^{\circledR}$. De bonnes corrélations modèles/essais sont obtenues après le recalage électromécanique des modèles. Celles-ci sont attribuées aux modèles EF raffinés dans le sens où ils ont considéré des aspects réalistes et désirables tels que l'équipotentialité des électrodes, les orientations (mêmes/opposées) des patches piézocéramiques, et les connexions (parallèles/séries) électriques correspondantes.
\end{abstract}

Mots clés : Amortissement piézocéramique shunté / tests expérimentaux / analyse par éléments finis / équipotentialité des électrodes / orientation des polarisations piézoélectriques / connexions électriques de patches / recalage électromécanique de modèles

\section{Introduction and state of the art}

The piezoceramic shunted damping (PSD) concept relies on the conversion, via a piezoceramic transducer bonded to the vibrating structure, of the mechanical energy to an electric energy that is dissipated through the resistive component of a shunting electronic circuit [1]. In analogy with the intrinsic electromechanical coupling

\footnotetext{
a Corresponding author:

gael.chevallier@supmeca.fr
}

coefficient (EMCC) that measures the energy conversion efficiency of a piezoceramic material [2-5], the generalized (or effective) EMCC parameter was introduced [6-9] to measure the patches energy conversion when they are bonded to, or integrated in, a host structure [10,11]. Moreover, the added damping was shown to be proportional to this parameter [12]. Hence, the latter can be used as a PSD performance indicator. The shunting circuit can be resistive (constituted by a simple resistance), resonant (or inductive, containing at least a resistance and 


\section{Nomenclature}

\begin{tabular}{|c|c|}
\hline$A$ & Patch electrode area $\left(\mathrm{m}^{2}\right)$ \\
\hline$C_{\mathrm{p}}^{\mathrm{S}}$ & Capacitance at constant strain of a patch $(\mathrm{nF})$ \\
\hline$C_{\mathrm{p}}^{\mathrm{T}}$ & Capacitance at constant stress of a patch $(\mathrm{nF})$ \\
\hline$f_{\mathrm{OC}}$ & Open-circuit natural frequency $(\mathrm{Hz})$ \\
\hline$f_{\mathrm{SC}}$ & Short-circuit natural frequency $(\mathrm{Hz})$ \\
\hline$h$ & Thickness of a patch $(\mathrm{m})$ \\
\hline$k_{31}$ & Material transverse electromechanical coupling coefficient \\
\hline$K$ & Effective electromechanical coupling coefficient \\
\hline $\mathrm{R}_{\mathrm{opt}}$ & Optimal electric resistance $(\Omega)$ \\
\hline$\in_{33}^{\mathrm{S}}$ & Transverse dielectric permittivity at constant strain $\left(\mathrm{F} . \mathrm{m}^{-1}\right)$ \\
\hline$\in_{33}^{\mathrm{T}}$ & Transverse dielectric permittivity at constant stress $\left(\mathrm{F} \cdot \mathrm{m}^{-1}\right)$ \\
\hline$\epsilon_{0}$ & Dielectric permittivity in void $\left(=8.854 \mathrm{pF} . \mathrm{m}^{-1}\right)$ \\
\hline$\omega_{\mathrm{SC}}$ & Short-circuit radial frequency $\left(\mathrm{rad} . \mathrm{s}^{-1}\right)$ \\
\hline $\bar{\omega}$ & Nominal radial frequency $\left(\operatorname{rad} . \mathrm{s}^{-1}\right)$ \\
\hline$\xi_{\text {add }}^{\mathrm{R}, \mathrm{RL}}$ & Added resistive $(\mathrm{R})$, resonant $(\mathrm{RL})$ shunted damping \\
\hline$\xi_{\mathrm{SC}, \mathrm{OC}}$ & Modal damping ratio for short-circuit/open-circuit patches electrodes \\
\hline$\xi_{\text {opt }}$ & Total damping ratio for optimal shunt resistance \\
\hline \multicolumn{2}{|r|}{$\begin{array}{l}\text { List of acronyms } \\
\end{array}$} \\
\hline $2 \mathrm{D}$ & Two-dimensional, \\
\hline $3 \mathrm{D}$ & Three-dimensional \\
\hline CFRP & Carbon fibre reinforced plastics \\
\hline DOF & Degrees of freedom \\
\hline $\mathrm{EBC}$ & Electric boundary conditions \\
\hline EMCC & Electromechanical coupling coefficient \\
\hline $\mathrm{EP}$ & Equipotential \\
\hline $\mathrm{FE}$ & Finite element \\
\hline FRF & Frequency response function \\
\hline $\mathrm{MBC}$ & Mechanical boundary conditions \\
\hline MSE & Modal strain energy \\
\hline NIDAQ & National instruments data acquisition \\
\hline $\mathrm{OC}$ & Open circuit \\
\hline $\mathrm{OP}$ & Opposite poling \\
\hline PSD & Piezoceramic shunted damping \\
\hline PW & Parallel wiring \\
\hline $\mathrm{PZT}$ & Lead Zirconate Titanate \\
\hline $\mathrm{SC}$ & Short circuit \\
\hline $\mathrm{SP}$ & Same poling \\
\hline SW & Series wiring \\
\hline UMAT & User material \\
\hline
\end{tabular}

an inductance in series or parallel) and capacitive (containing a simple capacitance with a positive or negative value) $[9,13]$. Switching between open-circuit (OC) and short-circuit (SC) electric states, or between OC and resistive or resonant shunted states, can also reduce vibrations [14]. It is worthy to mention the analogy between the resistive PSD and viscoelastic damping, and between the resonant PSD and the proof mass damping.

During the last three decades, the PSD concept was the focus of intense researches [13-15]. Its experimental evaluation and assessment have been conducted on simple structures, like bars, beams, plates and rings. By far, the cantilever beam with symmetrically (co-localised) bonded piezoceramic patches was the most experimented structure using various shunting circuits going from the simple resistor circuit [6] up to complex feedback [15] one. In this case of multiple patches, the poling (polarization) directions and the electric connections (wiring) of their electrodes affect the structure deformation state. Hence, when the patches have the same poling (SP) directions, they require electric parallel wiring $(\mathrm{PW})$; while when they have opposite poling (OP) directions, they require electric series wiring (SW) [16]. In both cases, this produces opposite electric fields in the patches so that when the bottom patch expands, the upper one contracts creating an upward pure bending of the cantilever beam.

Early PSD experimental evaluation and assessment tests have concerned a cantilever Aluminium beam on 
which two SP piezoceramic pairs were surface-bonded with a very thin conducting epoxy [6]. The beam was grounded and the positive electrodes were attached to the exterior electroded surfaces of the piezoceramic pairs. Resistive and resonant PSD tests were modelled and analysed using a single-mode mixed mechanical impedance/Ritz method [17]. The same electric wiring has been considered in [18] but for six piezoceramic pairs that were individually wired in parallel for multimode resonant PSD and a viscous damping was taken into account in the mechanical impedance formulation. The latter has been combined to the finite element (FE) method [8,12], a Navier analytical solution [19] and a shunt tuning method based on the measured electrical impedance [20] rather than pole placement and transfer function methods proposed in [6] and used in [7,8,12,17-19].

A modal strain energy (MSE) approach has been proposed and validated [21] on similar experiments as above. Here, it was clearly indicated that the patches have SP and PW. It was shown that the resistive PSD induced damping can be written as the product of the effective fraction of MSE stored in the piezoceramic material, an effective piezoceramic material loss factor and a frequency shaping factor. The first parameter is determined via a FE model, the second one is closely related to the material EMCC and the third one results from the shunting circuit dynamics. The proposed anelastic relaxation damping was later implemented as an integral hereditary material law in an ABAQUS ${ }^{\circledR}$ UMAT subroutine [22].

Few experiments have considered OP shunted piezoceramics. Hence, early in this decade, four pairs with inward OP piezoceramics bonded symmetrically on cantilever beams have been experimented for variable hybrid (shunted/active) damping based on control power requirement [23]. Recently, resistive PSD using outward $\mathrm{OP}$ piezoceramics bonded symmetrically with a conductive contact to a quasi-isotropic CFRP laminated cantilever beam were tested [24]. Here, the outside piezoceramics surfaces were coated with a conductive silver paint to form the positive electrodes across which the shunting resistance was connected. The contact was conductive but no information was given on the beam grounding. A similar configuration has been considered also recently for coupled-field analysis of a piezoelectric bimorph disc in a direct-write process [25]. Here, an inward OP bimorph piezoceramic beam without interface electrodes was shown to bend upward under series voltage conditions; this is the so-called series bimorph [16]. The modelling and analysis were made using ANSYS ${ }^{\circledR}$ PLANE223 two-dimensional (2D) piezoelectric FE.

Comparison of both SP and OP PSD configurations has been made only recently for multimode vibration reduction of a CD-ROM drive base [26]. The admittance of the piezoelectric structure, calculated using ANSYS ${ }^{\circledR}$ SOLID5 piezoelectric FE, was proposed as a PSD performance index. It was found that the magnitude of the admittance in case of OP is much smaller than that of the SP. It was concluded then that the vibration suppression of the piezoelectric shunt is small in case of OP. In the case of SP, the admittance obtained by numerical simulation correlates well with that obtained by experiments. These results were contradicted by the tests conducted recently [27] which gave similar experimental performance for OP and SP. It is thought then that the OP patches were not suitably wired and simulated in [26]. In [27], the $\mathrm{SP}$ and OP patches were connected in PW and SW, respectively, which is consistent with the PW for SP in [21] and the SW for OP in [25] as well as with parallel and series bimorphs definitions [16]. It is then necessary to indicate the poling directions and electric wiring for PSD experiments. Hence, the absence of these indications, as in $[28,29]$, renders the tests and their results useless for reference.

Use of commercial FE softwares for the modelling and analysis of PSD finds increasing interest. First, a UMAT ABAQUS ${ }^{\circledR}$ subroutine has been exploited as discussed above [22]; then, 2D 8-noded (PLANE223) [25] and three-dimensional (3D) 8-noded (SOLID5) [26, 30] piezoelectric FE of ANSYS ${ }^{\circledR}$ have been used. In [30], the electronic circuit was modelled using CIRCUIT94 specific element. Super element ANSYS ${ }^{\circledR}$ capability has been used, in [31], for modelling the piezoelectric patches assembled in MATLAB ${ }^{\circledR}$ to the host elastic structure FE model. The electrodes equipotential (EP) constraints were considered and model truncations have been implemented for both resistive and resonant shunts. The experimental and FE analyses have shown that the total modal damping equals the sum of the structural (Rayleigh) damping and the damping introduced by the piezoelectric patches. This damping superposition (additive) property has been used so that first, the inherent structural modal damping ratios $\left(\xi_{\mathrm{OC}}\right)$ were determined by the $-3 \mathrm{~dB}$ method for $O C$ electrodes; then, the same frequency band was applied so that the total modal damping $\left(\xi_{\text {opt }}\right)$ is determined; next, their difference has been used to quantify the increase in modal damping due to the applied passive electrical network; that is, $\xi_{\text {add }}^{\text {sh }}=\xi_{\text {opt }}-\xi_{\text {OC }}$. A parameter study has shown that modal damping ratios are very sensitive to uncertainties of the piezoelectric coupling matrix but not very sensitive to small changes in the optimal resistance. These results are consistent with obtained experimental ones [27] and theoretical one for the shunt parameter only [32]. Finally, MSC/NASTRAN ${ }^{\circledR}$ software, which has no piezoelectricity modelling capability, has been used to implement PSD [33]. For this purpose, the viscoelastic materials complex models of $[34,35]$ were adapted and combined to the impedance theory [6] for resistive and resonant PSD modelling. Notice that none of above simulations $[25,26,30,31]$ has considered the FE models updating.

This work presents, first, new laboratory tests for the experimental evaluation and assessment of the PSD concept for cantilever Aluminium thin (long) beams bonded symmetrically on their upper/lower surfaces with single pairs of small piezoceramic patches. Then, these tests are numerically modelled in 3D, analysed, and correlated using the commercial FE code ABAQUS ${ }^{\circledR}$ in order to measure the PSD efficiency via the so-called 


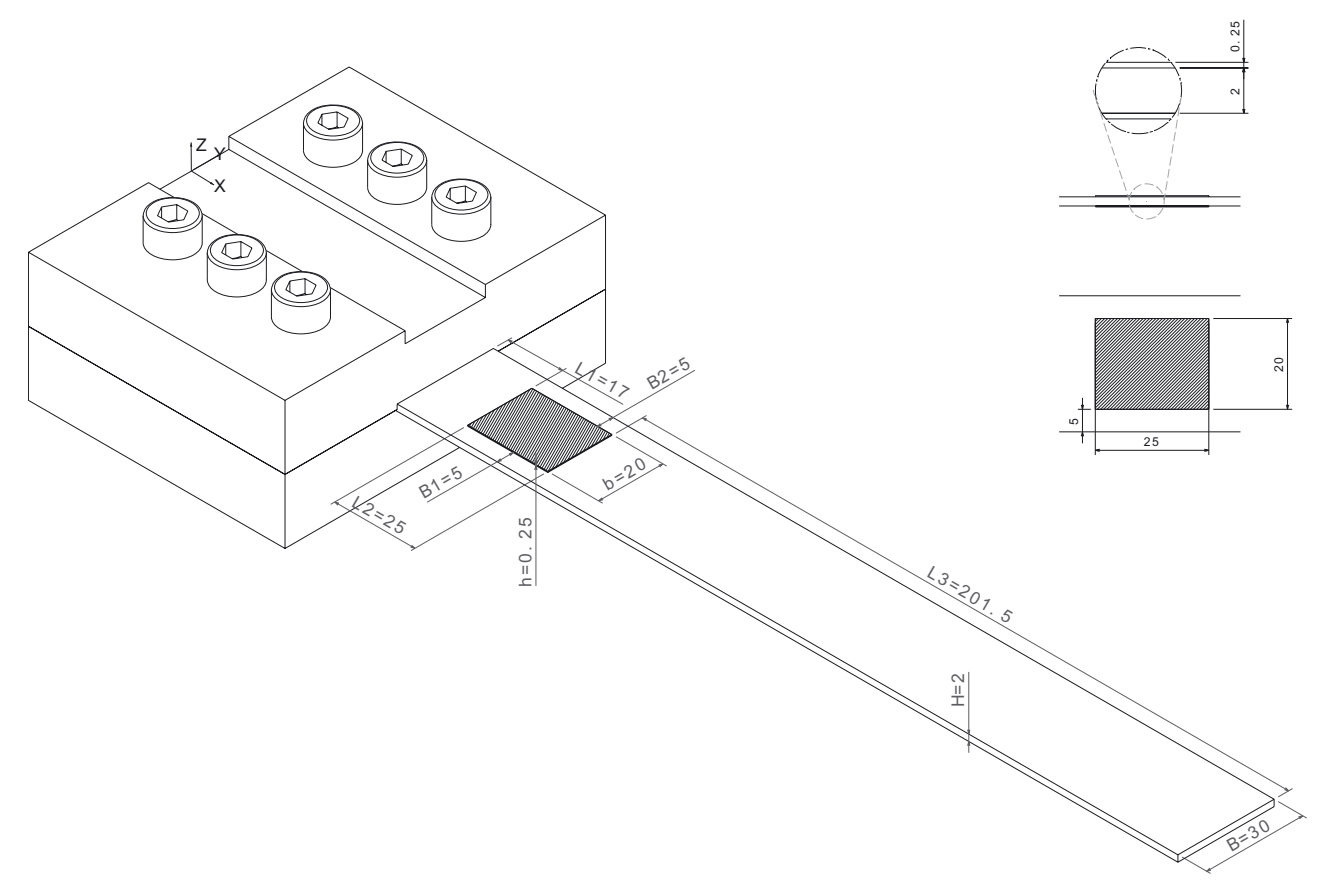

Fig. 1. Cantilever Aluminium beam with a bonded pair of PIC255 PZT patches (dim. in mm).

modal effective EMCC, which is post-processed from freevibrations analyses under $\mathrm{SC}$ and $\mathrm{OC}$ electrodes of the patches. Hence, two cantilever Aluminium beams with symmetrically bonded PIC255 piezoceramics (PZT), having either SP or OP, were analysed in free-vibrations for $\mathrm{SC}$ and $\mathrm{OC}$ electrodes without (w/o) or with EP constraints. The electric connections, representing the experimental PW and SW, were also modelled. To correlate with the experimental tests, the FE models electromechanical updating was also conducted. In contrary to the common practices, as attested by the above state-of-theart, these tests simulations can then be seen as refined in the sense that they consider the following realistic features:

- SP and OP are modelled using local coordinates systems. It is shown that a simpler alternative technique consists in using positive and negative piezoelectric matrices for $\mathrm{SP}$ and $\mathrm{OP}$, respectively, when filling the piezoelectric properties data.

- EP physical property was considered using linear constraints command for the electrodes electric degrees of freedom (DOF).

- SC and OC electric boundary conditions (EBC) were handled by imposing nil electric potential on the four electrodes for the SC EBC, and by letting the electrodes free of any load for the OC (with or w/o EP) EBC.

- PW and SW of the SP and OP patches configurations, respectively, were handled by adding electric connections equations to the EP electrodes.

- The FE models were updated in three ways: first, mechanically, by updating the mechanical boundary conditions (MBC), the experimental clamp, using linear springs which axial stiffness is tuned for each configuration so that the differences between $\mathrm{FE}$ and experimental fundamental $\mathrm{SC}$ frequencies are made minimum; then, electrically, by updating the transverse blocked dielectric constant using the measured blocked capacities of the individual patches; finally, electromechanically, by combining the previous two methods.

The original contributions of this work are (i) the experimental PSD performance assessment for both SP and OP bimorph configurations; (ii) the clarification of the electric wiring (connection) of SP and OP configurations; (iii) the electromechanically updated FE modelling with a commercial code of PSD experiments for different polarisations configurations; (iv) the assessment of the influence of the equipotential physical constraint on the modal effective EMCC. This work outcome could be of major interest to practitioners and researchers.

\section{Piezoceramic shunted damping concept testing}

\subsection{Test articles design and experimental setup}

Two test articles were designed and assembled for the experimental evaluation and assessment of the PSD concept. They consist of Aluminium cantilever beams with 0.25 mm-thick PIC255 PZT patches (purchased from PI Ceramics) glued symmetrically with a conductive epoxy adhesive on their top and bottom surfaces near the clamp (Fig. 1) in order to get measurable effective EMCC at least for the first bending mode. Focus is made here on the pure bending modes of the beams which induce expansion and contraction strains on their external faces. 

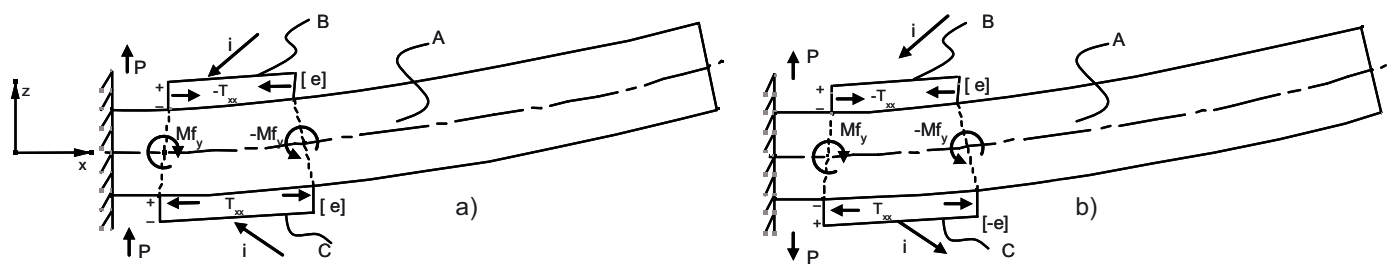

Fig. 2. Piezoceramic patches bonding configurations: (a) SP. (b) OP.

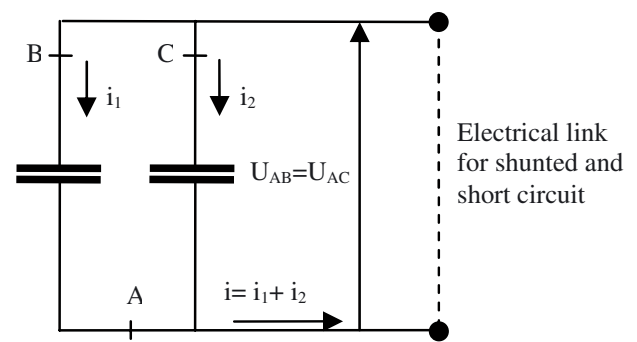

(a)

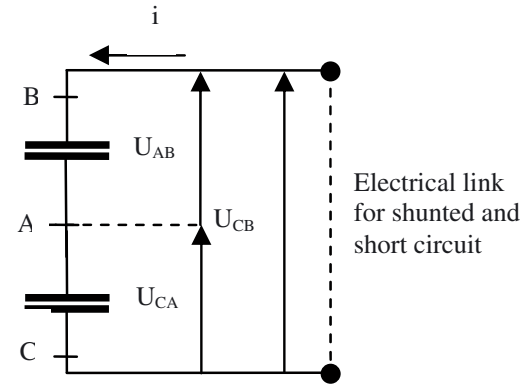

(b)

Fig. 3. Electric connections: (a) Parallel wiring (for SP). (b) Series wiring (for OP).

Since the patches are polarized along the thickness direction and work in their extension response, as sketched in Figure 2 for the fundamental mode, this can be reached by bonding them so that they have either positive SP (Fig. 2a) or outward OP (Fig. 2b) directions.

As it is well known, a piezoceramic patch generates electric charges, hence a flowing electric current, when it is deformed. The sign of this current depends on the signs of the imposed strains on the patches as in Figure 2. Hence, above bonding configurations have to be connected electrically in parallel (Fig. 3a) and in series (Fig. 3b), respectively. This leads to respective equivalent capacitance of wired piezoceramic patches of half and twice that of each patch. It is clear from Figure 4 that SP and $\mathrm{OP}$ patches have to be $\mathrm{PW}$ and SW, respectively; otherwise, no current is flowing in the wired pair and no added PSD can be expected. For better readability, PW and SW patches electric connections acronyms will be used mainly in this testing section, while those of SP and OP patches bonding configurations will be used mainly in the FE modelling section.

The bending modes of the beams are excited with an electromagnetic shaker. The latter is plugged near the beam clamp in order to minimize its mass coupling. Since only the first modes are measured there is no modal coupling between the shaker and the beam. A white noise generator is used to drive the shaker in a [10-1000] $\mathrm{Hz}$ frequency range. The acceleration is measured using an electromagnetic sensor located near the beam tip. This position is a good compromise in order to get the largest displacement for the first two bending modes. Both the generator and the sensor are linked to a National Instrument Data Acquisition (NIDAQ) card (Fig. 5) which measures their signals. Using the latter, SC and OC frequency response functions (FRF), for both electrical connections, are plotted in order to extract the natural frequencies and modal damping ratios. The latter are calculated using the classical $-3 \mathrm{~dB}$ approach from the FRFs; these were computed using the $\mathrm{H} 1$ transfer function after averaging the signals acquired during 400 blocks. To get good EMCC calculation accuracy, the frequency resolution is taken as $0.039 \mathrm{~Hz}$. This value is obtained with the above frequency range and with blocks of 16384 samples. Finally, to evidence the effect of the passive damping induced by the shunted piezoceramics, all the other causes of damping were minimized by using an electromagnetic non contact sensor, a clamp as stiff as possible (a heavy steel mass as in Fig. 1), and specific electric wires, as thin as possible.

\subsection{Experimental PSD performance evaluation and assessment}

Some preliminary tests were first conducted. They consist of measuring, for both series and parallel electrical connections, the bonded patches individual and wired (equivalent) capacitances at constant strain and the openloop (without shunt) OC and SC modal properties (FRFs, natural frequencies, damping ratios).

Individual and wired bonded patches capacitances (at constant strain) are measured using a multi-meter for a nominal frequency of $100 \mathrm{~Hz}$. The obtained values are compared in Table 1 to the theoretical ones resulting from the expression of the capacitance at constant strain $(S)$ in term of that at constant stress $(T)$ and material extension EMCC, $k_{31}$ :

$$
C_{\mathrm{p}}^{\mathrm{S}}=C_{\mathrm{p}}^{\mathrm{T}}\left(1-k_{31}^{2}\right)
$$

with

$$
C_{\mathrm{p}}^{\mathrm{T}}=\frac{\epsilon_{33}^{\mathrm{T}} A}{h}
$$


Table 1. Measured and theoretical blocked capacitances (nF).

\begin{tabular}{|c|c|c|c|c|c|c|}
\hline Wiring & Side & $\begin{array}{l}\text { Measured } \\
\text { Individual }\end{array}$ & $\begin{array}{l}\text { Theoretical } \\
\text { Individual }\end{array}$ & $\begin{array}{l}\text { Measured } \\
\text { Equivalent }\end{array}$ & $\begin{array}{l}\text { Theoretical } \\
\text { Equivalent }\end{array}$ & $\begin{array}{c}\text { Relative } \\
\text { Difference }(\%)\end{array}$ \\
\hline \multirow{2}{*}{ Parallel } & left & 17.9 & \multirow{4}{*}{27.2} & \multirow{2}{*}{36} & \multirow{2}{*}{54.5} & \multirow{2}{*}{33.8} \\
\hline & right & 17.6 & & & & \\
\hline \multirow{2}{*}{ Series } & left & 23 & & \multirow{2}{*}{12} & \multirow{2}{*}{13.6} & \multirow{2}{*}{11.8} \\
\hline & right & 23.8 & & & & \\
\hline
\end{tabular}

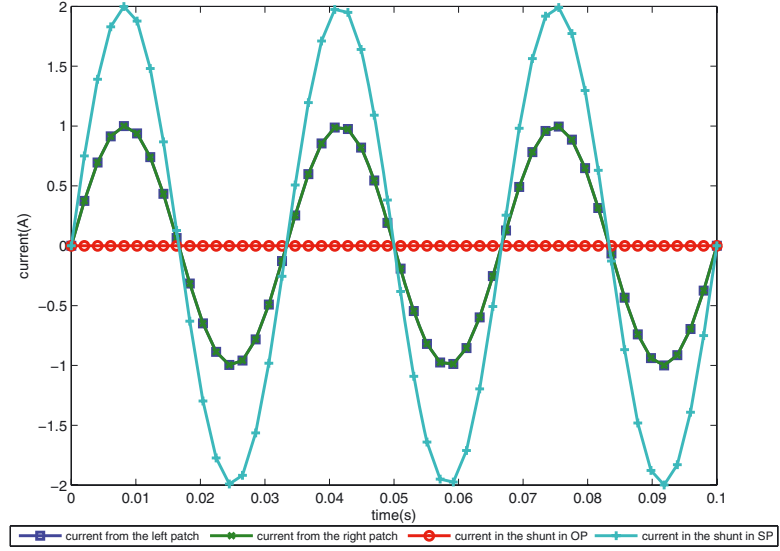

(a)

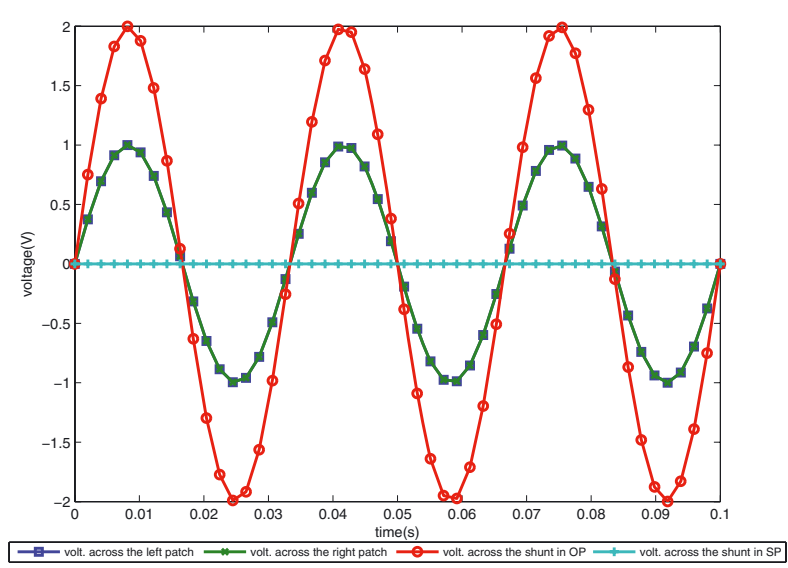

(b)

Fig. 4. Flowing currents (a) and voltages (b) in individual, $\mathrm{SP}$ and $\mathrm{OP}$ patches.

where $\epsilon_{33}^{\mathrm{T}} / \epsilon_{0}=1750$ and $k_{31}=0.35$ are the PIC255 PZT relative transverse dielectric constant at free stress and EMCC; $h$ and $A$ are its thickness and electrode area. The observed relative differences may be due, on one hand, to the quality of the manual gluing procedure of the patches to the beams for both electrical connections; it seems that the series configuration was better experimentally prepared than the parallel one. On the other hand, these deviations may be also due to the fact that the measured capacitance is in fact the static one which value lies between those of the free and blocked capacitances.

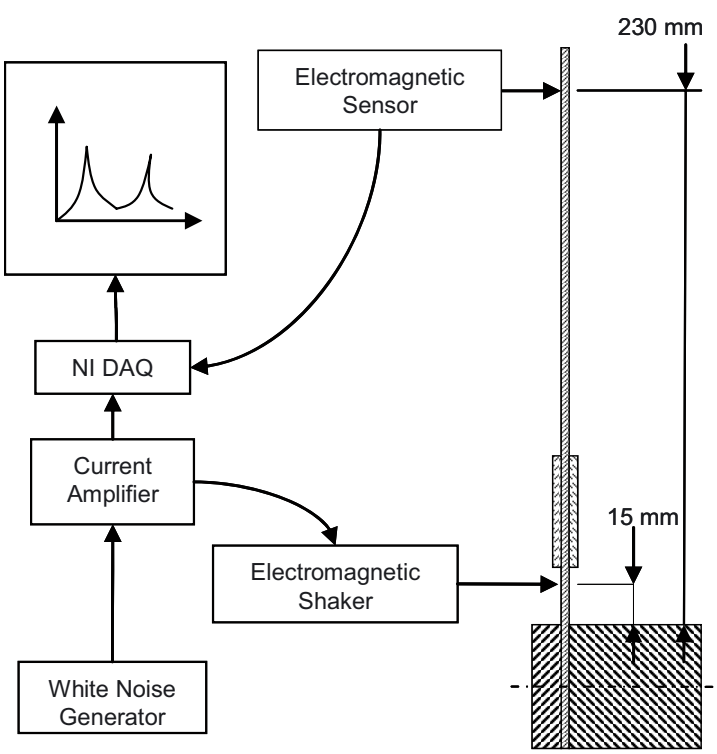

Fig. 5. Experimental setup.

The made error depends mainly on the MSE fraction in the patches [9]. Besides, the dielectric bonding glue may affect the OP configuration capacitance and OC frequency (hence EMCC) measurements more than the SP ones since the beams were not grounded. Nevertheless, the bonding layers capacities were measured and found to be around one hundred times lower that those of the individual patches. No specific measurement difficulties were encountered with the OP configuration.

Measured frequency response functions of the first two bending modes of series and parallel electrical connections with OC electrodes of the patches are shown in Figure 6. The differences ( $<3 \%$ for the frequencies) between the two electrical connections can be explained by the geometrical defects and the manual gluing procedure. The equivalent capacitances of both configurations should induce only small differences at this testing stage.

Open-loop series and parallel connections measured $\mathrm{SC}$ and $\mathrm{OC}$ natural frequencies and damping ratios of the first and second bending modes are given in the corresponding FRFs shown in Figures 7 and 8, respectively. It can be noticed that the open-loop measured damping ratios are rather small and that, due to the experimental conditions, they can not be further reduced.

For the resistive PSD concept experimental evaluation and assessment, the maximum added damping is 


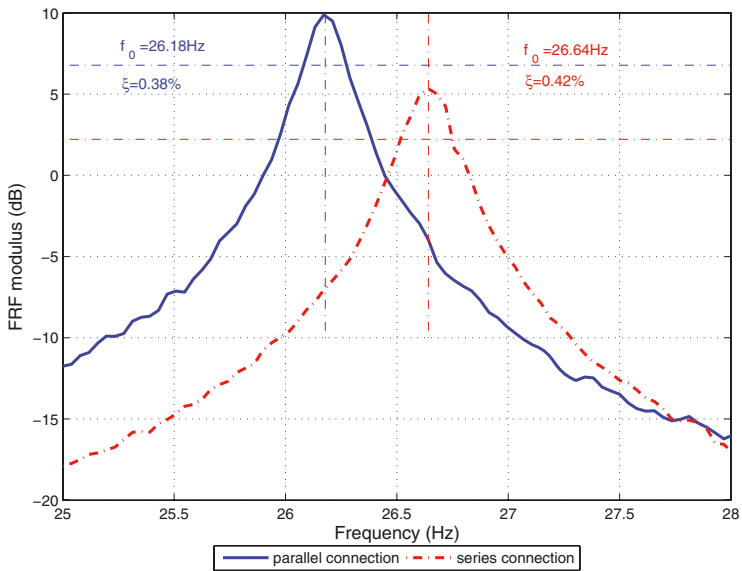

(a)

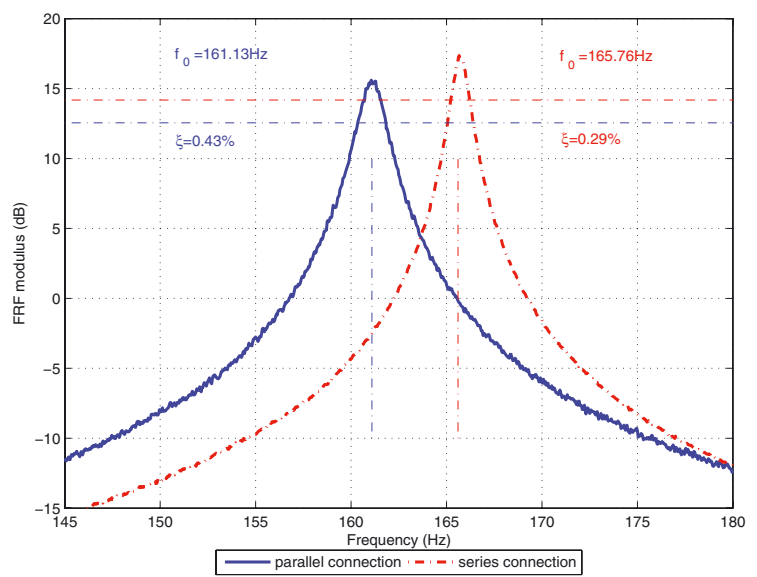

(b)

Fig. 6. OC measured FRF of SW and PW configurations: (a) First mode. (b) Second mode.

calculated using the measured $\mathrm{OC}$ and SC natural frequencies for both SW and PW via this approximate relation $[7-9]$ :

$$
\xi_{\mathrm{add}}^{\mathrm{R}} \approx \frac{K^{2}}{4}
$$

with,

$$
K^{2}=\frac{f_{\mathrm{OC}}^{2}-f_{\mathrm{SC}}^{2}}{f_{\mathrm{SC}}^{2}}
$$

Then, optimal resistances are computed from measured or calculated capacitances (Tab. 1) and compared to those obtained from an experimental parametric analysis. Corresponding calculated and measured damping ratios are also compared for validation. Hence, using equations (2), in conjunction with the $\mathrm{SC} / \mathrm{OC}$ measured frequencies given in Figures 7 and 8, the corresponding modal effective EMCC and theoretical maximum added PSD are calculated and summarized in Table 2 . In the latter, $\xi_{\text {opt }}$ is the total damping ratio calculated as the sum of the $\mathrm{SC}$ damping ratio $\left(\xi_{\mathrm{SC}}\right)$ that can be seen as the nominal damping and the added one $\left(\xi_{\text {add }}^{\mathrm{R}}\right)$ obtained for the optimal resistive shunt. This is a different use than in [31] of the damping additive property since the added PSD

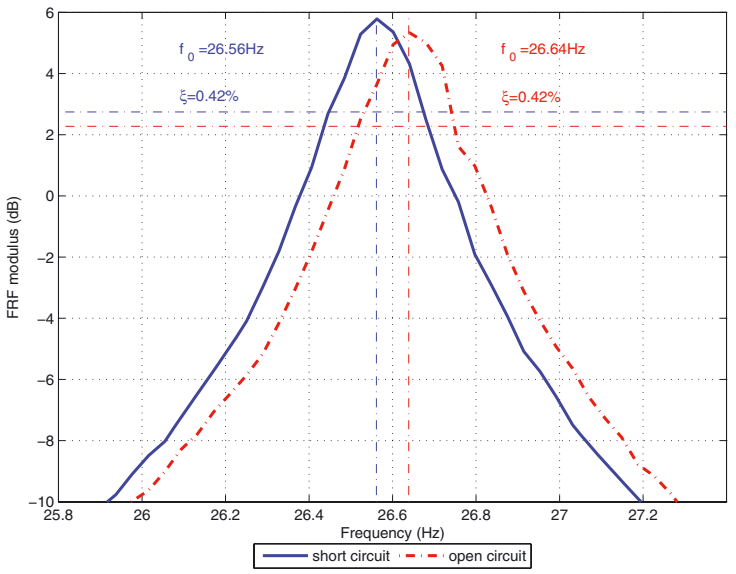

(a)

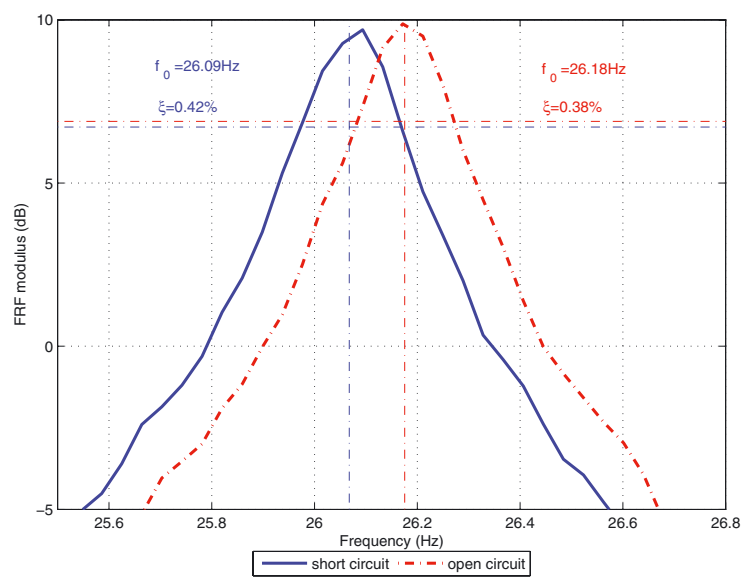

(b)

Fig. 7. First mode open-loop SC/OC FRF for: (a) SW. (b) PW.

was deduced there from measured OC and total damping $\left(\xi_{\text {add }}^{\text {sh }}=\xi_{\text {opt }}-\xi_{\mathrm{OC}}\right)$, while here, it is estimated via equation (2a) and the total damping is computed as $\xi_{\text {opt }}=\xi_{\mathrm{SC}}+\xi_{\mathrm{add}}^{\mathrm{R}}$; i.e., only $\xi_{\mathrm{SC}}$ is measured. Low values of the added damping ratios can be noticed from Table 2, in particular for the second mode. This can be expected from the corresponding modal effective EMCC that can be seen as a PSD performance indicator. It is worthy to mention that equation (2a) is valid only for low modal effective EMCC. It is deduced from an exact relation that was obtained from single mode PSD transfer functions root loci [9]; hence, equation (2a) is also limited to well spaced modes. The exact and approximate resistive PSD formulas comparison and their validation with experimental data [6] were made in [12].

To provide the maximum added piezoelectric shunted damping at the nominal radial frequency $\bar{\omega}=\omega_{\mathrm{SC}}=$ $2 \pi f_{\mathrm{SC}}$, the optimal resistance should be chosen as [6]:

$$
R_{\mathrm{opt}}=\frac{\sqrt{1-k_{31}^{2}}}{C_{\mathrm{p}}^{\mathrm{S}} \bar{\omega}}
$$




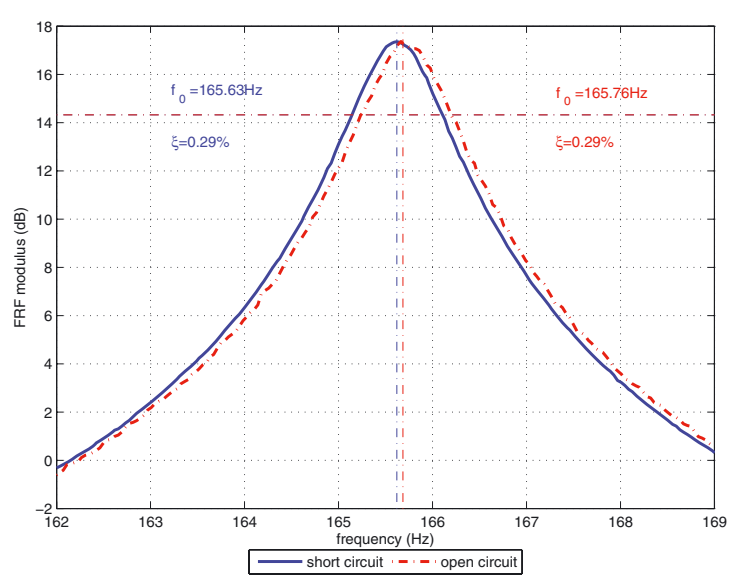

(a)

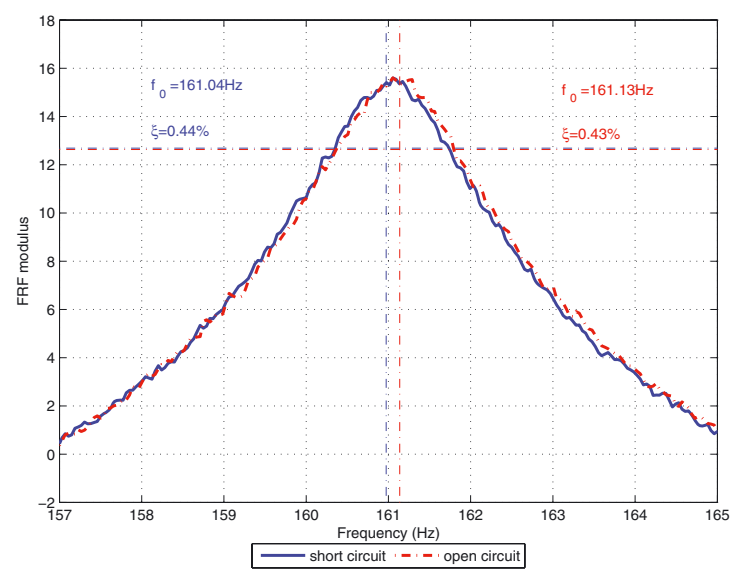

(b)

Fig. 8. Second mode open-loop SC/OC FRF for: (a) SW. (b) PW.

Table 2. Modal effective EMCC and predicted optimal damping ratios.

\begin{tabular}{ccccc}
\hline Mode & \multicolumn{2}{c}{1} & \multicolumn{2}{c}{2} \\
\hline Wiring & Series & Parallel & Series & Parallel \\
$K(\%)$ & 7.77 & 8.31 & 3.96 & 3.34 \\
$K^{2}(\%)(2 \mathrm{~b})$ & 0.6 & 0.69 & 0.16 & 0.11 \\
$\xi_{\text {add }}^{R}(\%)(2 \mathrm{a})$ & 0.15 & 0.17 & 0.04 & 0.03 \\
$\xi_{\mathrm{SC}}(\%)$, measured & 0.42 & 0.42 & 0.29 & 0.44 \\
$\xi_{\text {opt }}\left(=\xi_{\text {SC }}+\xi_{\text {add }}^{R}\right)(\%)$ & 0.57 & 0.59 & 0.33 & 0.47 \\
$\xi_{\text {SC }} \%$ increase & 36 & 45 & 14 & 7 \\
\hline
\end{tabular}

With this relation, the optimal resistances are computed using the capacitances given in Table 1 for both electric connections and the first two bending modes. Experimental capacitances were used to help for minimizing the gap between predictions and measurements and to obtain predicted damping ratios of Table 2. Moreover, to validate the latter, an experimental parametric analysis was performed by varying the shunt resistor for both modes and connections. Corresponding results are summarized in Table 3. The latter indicates that, for the considered connections and modes, the theoretical resistances are in the interval defined by the best tested resistances. It can
Table 3. Optimum resistance and damping of a resistively shunted cantilever Aluminium beam.

\begin{tabular}{cccccc}
\hline \multicolumn{2}{c}{ Mode } & \multicolumn{2}{c}{1} & \multicolumn{2}{c}{2} \\
\hline \multicolumn{2}{c}{ Wiring } & \multicolumn{3}{c}{ Series } & Parallel Series Parallel \\
\hline Theoretical & $R_{\text {opt }}(\mathrm{k} \Omega)(3)$ & 468 & 159 & 75 & 26 \\
predictions & $\xi_{\text {opt }}(\%)($ Tab. 2) & 0.57 & 0.59 & 0.33 & 0.47 \\
\hline Experimental & $R_{\text {opt }}(\mathrm{k} \Omega)$ & 440 & 150 & 70 & 15 \\
analyses & $\xi_{\text {opt }}(\%)$ & 0.56 & 0.55 & 0.34 & 0.49 \\
\hline
\end{tabular}

be noticed also that a very good agreement is also reached between predicted and measured optimal damping ratios. These results confirm the low sensitivity of the resistive PSD to the resistor tuning parameter, as in $[31,32]$, and the damping additive property, as in [31]. Also, the added PSD estimation using the modal effective EMCC, as defined in equations (2), is here experimentally verified; thus, this parameter can be used as a PSD performance indicator.

\subsection{Modal effective EMCC as a PSD performance indicator}

From above experiments, it appears clearly that the knowledge of the modal effective EMCC provides a good estimation, via equation (2a), of the maximum added resistive shunted damping. In fact, its square root is also a very useful damping parameter since it provides an estimation of the maximum added damping of resonant shunting via this approximate relation (see [9] for example):

$$
\xi_{\text {add }}^{\mathrm{RL}} \approx \frac{K}{2}
$$

The same comments on equation (2a), at the end of the paragraph that follows it, are also valid here for equation (4), except that the exact and approximate resonant PSD formulas comparison and their validation with experimental data [6] were made in [8].

Therefore, to design PSD applications, it is capital to know the modal effective EMCC; then, its square and square root can inform on the expected maximum added resistive and resonant $\mathrm{PSD}$, respectively. Besides, the use of SC and OC modal analyses renders its calculation easy by commercial codes (available for industry) and makes it a good PSD design criteria. For this reason, the upcoming numerical analyses and test/model correlations will focus only on the modal effective EMCC evaluation and assessment with regards to the above listed realistic features (see the end of the introduction section).

\section{PSD tests FE modelling, analyses and correlations}

\subsection{Tests FE modelling}

The tested cantilever beams, as sketched in Figure 1, with SP and OP symmetrically bonded piezoelectric 


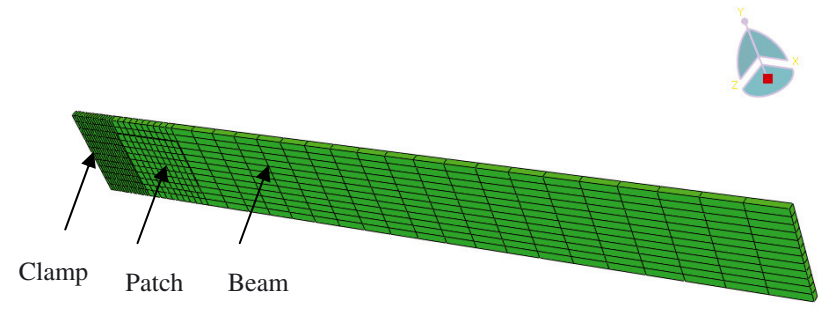

Fig. 9. FE model of the tested cantilever smart beams.

patches and connected electrically in PW and SW, respectively, were modelled using ANSYS multiphysics and ABAQUS ${ }^{\circledR}$ FE commercial codes, the only ones available for us to run coupled piezoelectric analysis. However, only the modelling procedure with $\mathrm{ABAQUS}^{\circledR}$ is retained here because it is thought that it presents higher research and practical added values. ANSYS multiphysics procedures for this benchmark can be found in [36] and in [37] for another benchmark.

The encountered first problem was the incomplete set of PIC255 material data provided by the supplier; to overcome it, the useful provided ones for a $3 \mathrm{D} \mathrm{FE}$ analysis were completed using the procedure described in [37]. The second problem was to fill the code GUI for the materials properties with the right data since the software does not use the IEEE Standards on piezoelectricity notations [3] regarding the shear electromechanical (elastic and piezoelectric) constants. Also, the code uses the 4 indices notations for the constitutive equations but expects 2 indices notations input data (see Appendix A).

After a preliminary FE model convergence analysis, the cantilever adaptive beam has been discretized using quadratic (20-nodes) brick elements so that the resulting FE model has 885 elements and 8896 nodes; that is, C3D20R ( $R$ for reduced integration) and C3D20ER (E for electric) were used for the Aluminium beam and piezoceramic patches, respectively (Fig. 9).

To represent the different poling directions for SP and $\mathrm{OP}$ configurations, local coordinates systems were attached to the individual patches. For this purpose, it is necessary to create a "Datum CSYS" for each patch and to assign an orientation so that, for the SP, both patches systems have the same orientation, and for the OP, one of the patches systems will be turned to $180^{\circ}$ of the other patch system around the first axis (Fig. 10).

For each electric connection (series or parallel), there are two wiring ways: SC and OC (with or without equipotentiality). These are reached using kinematics linear relations via ABAQUS ${ }^{\circledR}$ constraints command. Consequently, sets and constraints are created in terms of the electric degree of freedom, DOF9, to have the various configurations types. Hence, there are two constraint equations for each connection type. First, the different sets are defined for DOF9 as follows:

$-S_{\mathrm{P} 1}^{\mathrm{ext}}$ : all nodes of the patch 1 external surface except a node.

$-N_{\mathrm{P} 1}^{\text {ext }}$ : the remaining node of the patch 1 external surface.
- $S_{\mathrm{P} 1}^{\text {int }}$ : all nodes of the patch 1 internal surface except a node.

- $N_{\mathrm{P} 1}^{\mathrm{int}}$ : the remaining node of the patch 1 internal surface in contact with the beam.

$-S_{\mathrm{P} 2}^{\text {ext }}$ : all nodes of the patch 2 external surface except a node.

$-N_{\mathrm{P} 2}^{\text {ext }}$ : the remaining node of the patch 2 external surface.

$-S_{\mathrm{P} 2}^{\text {int }}:$ all nodes of the patch 2 internal surface except a node.

$-N_{\mathrm{P} 2}^{\text {int }}$ : the remaining node of the patch 2 internal surface in contact with the beam.

- $N_{\text {beam }}^{1}$ : a node of the beam in contact with the patch 1 .

- $N_{\text {beam }}^{2}$ : a node of the beam in contact with the patch 2 .

For each connection, realized wirings (OC and SC) are represented by their equivalent linear relations (Fig. 11):

$$
\begin{array}{r}
N_{\mathrm{P} 2}^{\text {int }}-N_{\mathrm{P} 1}^{\text {int }}=0 \\
N_{\mathrm{P} 1}^{\text {ext }}-N_{\text {beam }}^{1}=0 \\
N_{\mathrm{P} 2}^{\text {ext }}-N_{\text {beam }}^{2}=0 \\
N_{\mathrm{P} 2}^{\text {int }}-N_{\mathrm{P} 1}^{\text {int }}=0 \\
N_{\mathrm{P} 2}^{\text {ext }}-N_{\mathrm{P} 1}^{\text {ext }}=0 \\
N_{\mathrm{P} 2}^{\text {int }}-N_{\mathrm{P} 1}^{\text {int }}=0
\end{array}
$$

Also, applying SC or OC EBC is realized directly in the GUI by selecting the nodes of the electrodes to apply the EBC. Hence, for the SC condition, it is enough to select the nodes of the patches four faces and to apply on them a nil potential. While, for the OC case, the faces of patches are charge free. The usual way is to not apply any electric condition. However, for physical reasons, the EP condition has to be added by coupling the nodes of each face of the patches. Hence, to express the equipotentiality constraints of the patches surfaces, the following relationships are used between the electric DOFs (DOF 9):

$$
\begin{aligned}
& S_{\mathrm{P} 1}^{\mathrm{ext}}-N_{\mathrm{P} 1}^{\mathrm{ext}}=0 \\
& S_{\mathrm{P} 1}^{\mathrm{int}}-N_{\mathrm{P} 1}^{\mathrm{int}}=0 \\
& S_{\mathrm{P} 2}^{\text {ext }}-N_{\mathrm{P} 2}^{\mathrm{ext}}=0 \\
& S_{\mathrm{P} 2}^{\mathrm{int}}-N_{\mathrm{P} 2}^{\mathrm{int}}=0
\end{aligned}
$$

An easier alternative technique to simulate the electric connections is also proposed; it is based on the polarization orientation by changing the sign of the patches individual piezoelectric matrices. For this, first, a unique piezoelectric matrix with same signs is used for both patches as in Figures 12a and 12b for the SP and OP configurations; then, the piezoelectric matrix sign of one of the patches is changed in order to get $\mathrm{OP}$ and $\mathrm{SP}$ ones, respectively. However, this requires the definition of two different materials, one for each patch as in Figures 12c, 12d. 

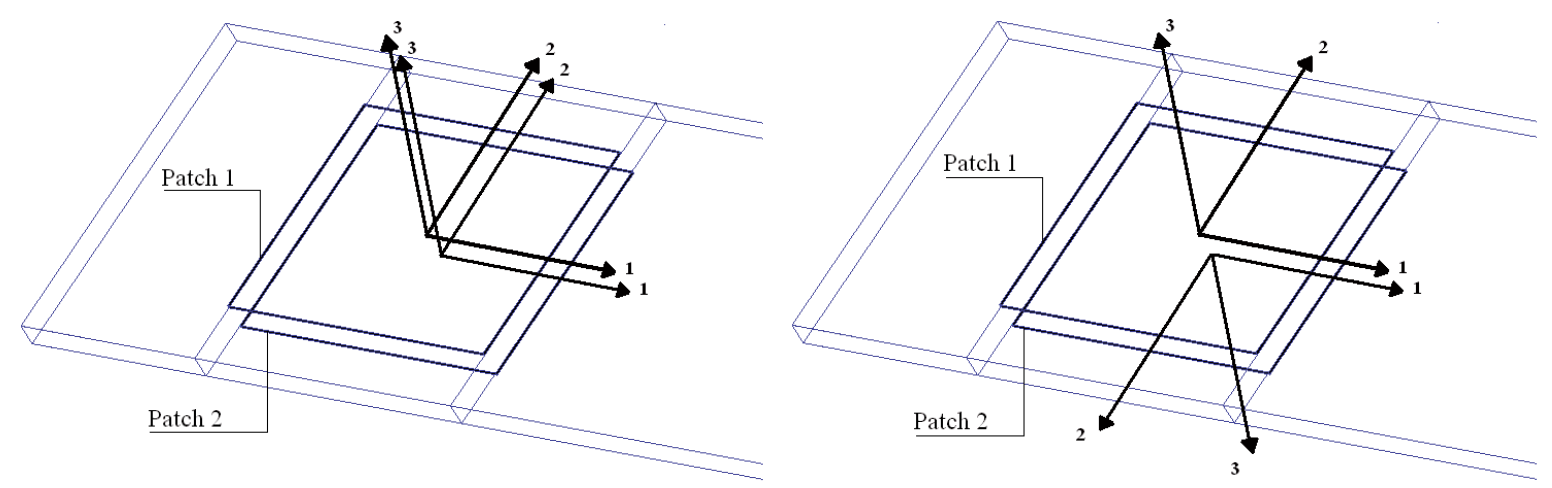

Fig. 10. SP and OP modelling.

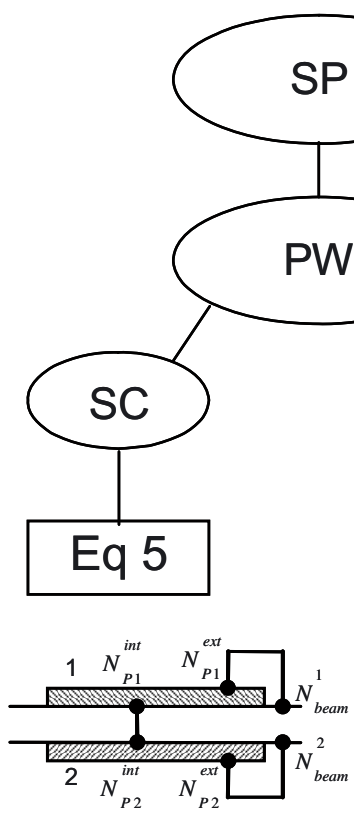

Fig. 11. Linear relations for modelling PW and SW.

Same piezoelectric matrices for the patches (use of local coordinate systems)

Opposite piezoelectric matrices for the patches (replace the use of local coordinate systems)

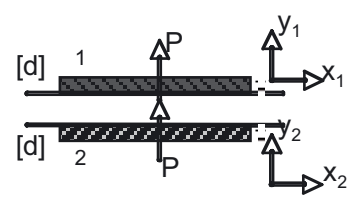

(a) SP

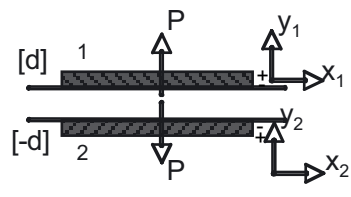

(c) $\mathrm{OP}$

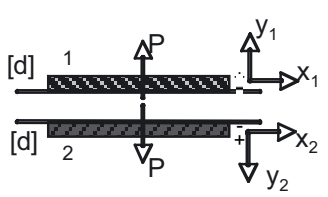

(b) $\mathrm{OP}$

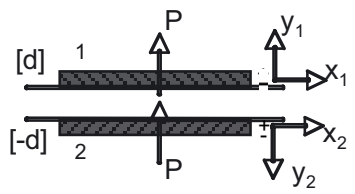

(d) SP

Fig. 12. SP/OP modeling using local coordinate systems or changing piezoelectric matrices signs. 


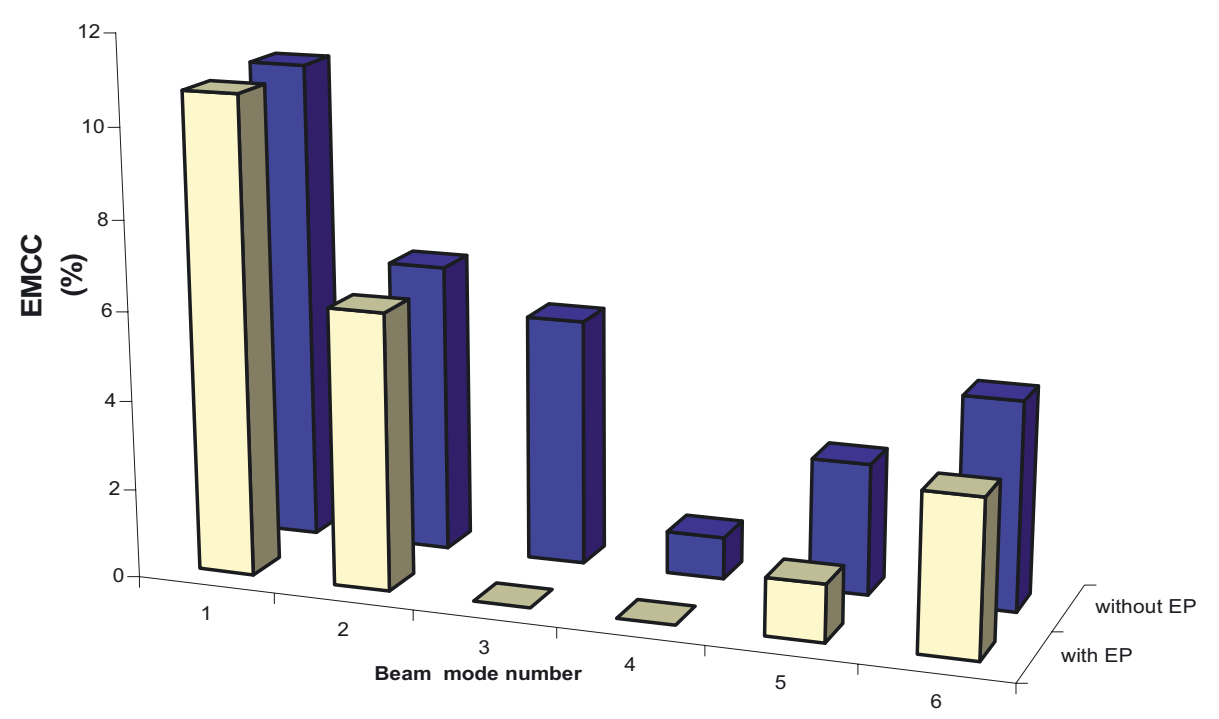

Fig. 13. EP (decoupling) effect on the modal effective EMCC.

\subsection{Preliminary FE analyses}

Preliminary FE free vibration analyses (without models updating), using the iterative block subspace algorithm, of the four configurations, shown in Figure 12, for the OC case with or without applying the EP condition, equation (8), and with or without the electric connections equations (5-7), have shown that both modelling techniques of the polarisation orientations are equivalent and that the electric connection equations (5-7) have no influence on the frequencies. Also, SP and OP configurations gave the same frequencies in contrary to the experimental results; this may be due to the patches bending layers and the damping that have not been considered in the FE models.

The obtained results for the first six modes are shown in Figures 13 and 14. The latter show that the effect of the EP condition on the frequencies is very small but is important on the modal effective EMCC in particular for marginally coupled modes as for the last two ones. Moreover, the in-plane (plate) bending (3rd) and torsion (4th) modes (see Fig. 15) become uncoupled when the $\mathrm{EP}$ is applied because their potential distributions are unsymmetric (see Fig. 14); hence, the application of the $\mathrm{EP}$ constraint makes their electrode potential distribution average nil leading to identical SC and OC frequencies, hence a nil EMCC. Figure 14 shows clearly that when the EP is not considered in the piezoelectric FE analyses, the electric potential is no longer uniform on the patches electrodes; this is not consistent with the physics. This figure was obtained under the condition that the patchesto-beam interfaces are grounded; otherwise the uniform potential distribution overpasses the patches areas.

First two modes (Fig. 16) modal effective EMCC FE results (without models updating) are compared to the experimental ones in Figure 17 which indicates that deviations are important for both modes. Models updating with measurements are then necessary to reduce simulations errors.

\subsection{Electromechanical updating for test/model correlation}

For better correlations purpose, FE models were updated both mechanically and electrically. Mechanical updating was first made by removing the clamp then blocking only the two translations in the cross-section plan. The translation in the beam axial direction was let free, but a spring is added for the free DOF which stiffness is distributed on all the face nodes using ABAQUS ${ }^{\circledR}$ Spring/Dashpots function. This modification allows the first section to rotate around the y-axis; thus the clamp is less stiff and the modal frequencies are lower. Different updating stiffness values per node $\mathrm{k}_{n}$ were tested using the classical trial and error technique (more details can be found in $[11,37]$ ). Using spring stiffness values of $2.05 \mathrm{MN} / \mathrm{m}$ and $2.48 \mathrm{MN} / \mathrm{m}$ for the SP and OP configurations, respectively, led to relative deviations of $0 \%$ for the fundamental frequency of both configurations and $1.22 \%$ and $2.65 \%$ for the second mode under these configurations, respectively. On the other hand, electric updating was reached by using the computed transverse blocked dielectric constant from the measured (see Tab. 1) SP and OP blocked capacitances (individual) using this formula:

$$
\epsilon_{33}^{\mathrm{S}}=\frac{C_{\mathrm{p}}^{\mathrm{S}} h}{A}
$$

After electromechanical updating, computed SP and OP OC (with EP) modal frequencies and effective EMCC are now different as given in Table 4 . When compared to experimental results of the first two modes, a great enhancement of the test/model correlation can be noticed as shown in Table 5. The latter shows higher deviations for the second mode (slightly coupled) than for the first one (coupled) which can be considered satisfactory; this can be explained by the low EMCC values of the former; that is, although the difference between $\mathrm{SC}$ and $\mathrm{OC}$ values are very small, their squared values are amplified through the EMCC evaluation. 


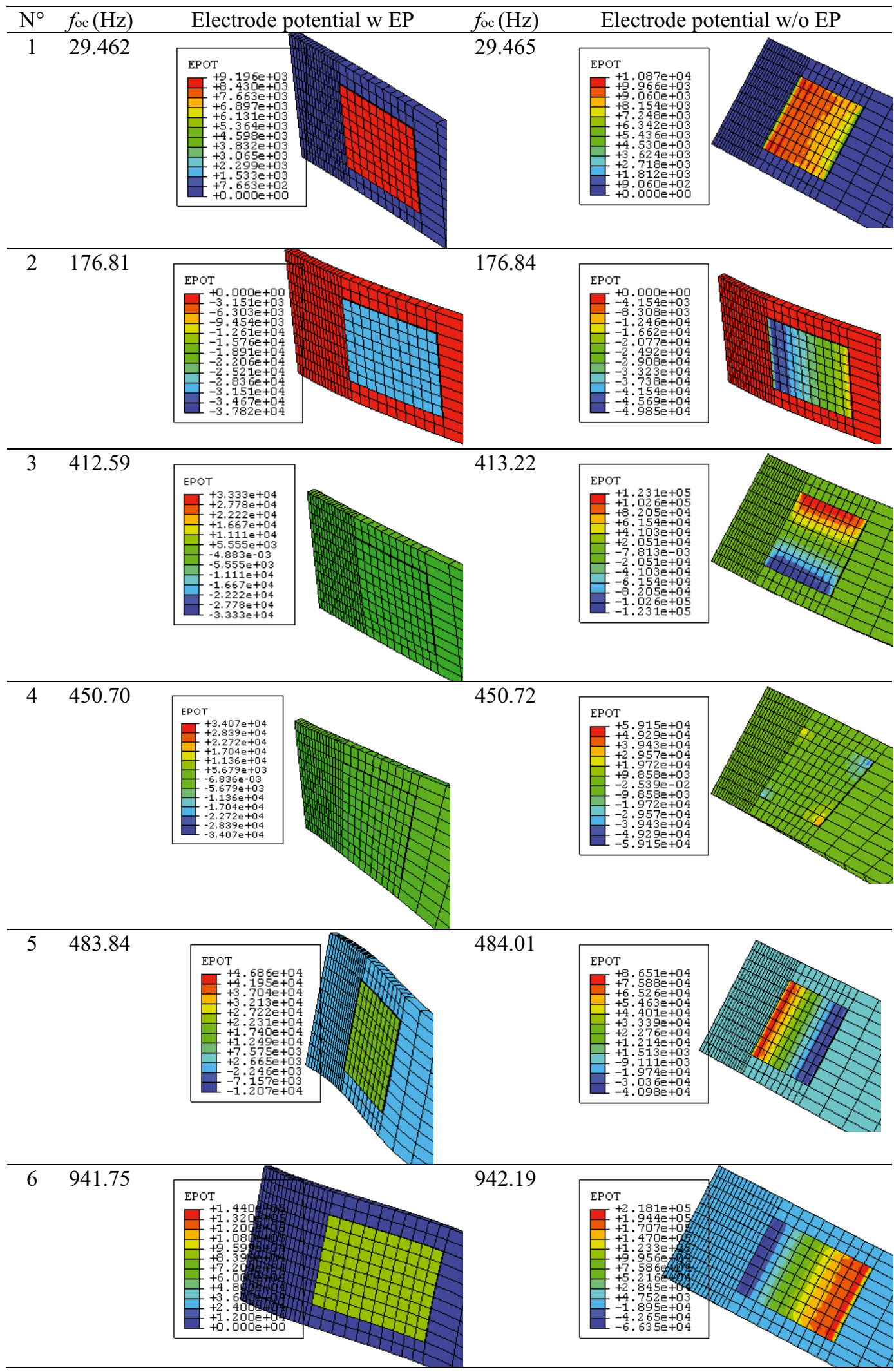

Fig. 14. Electrodes potential distributions w vs. w/o EP for OC SP patches (grounded interfaces). 


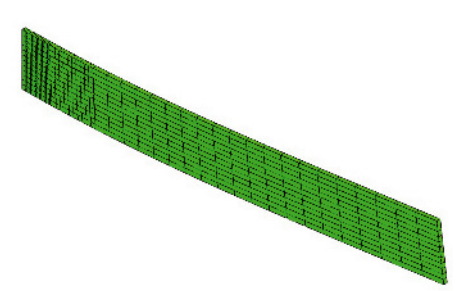

(a)

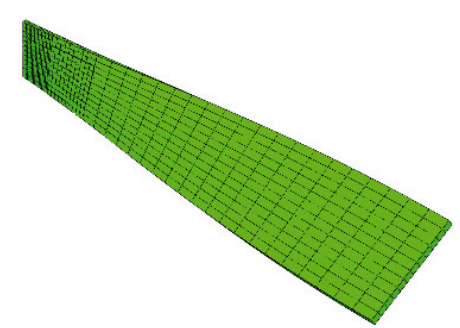

(b)

Fig. 15. Mode shapes of the decoupled modes by the EP constraint: (a) Mode 3. (b) Mode 4.

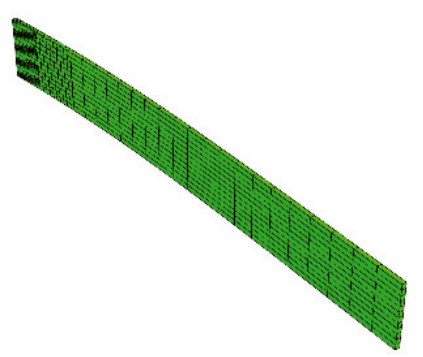

(a)

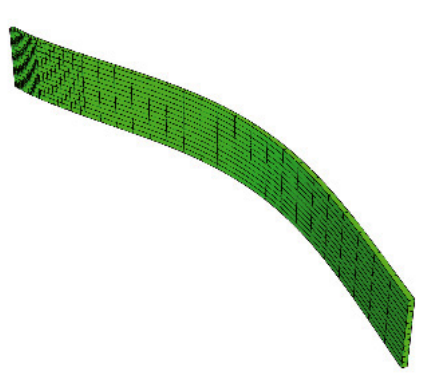

(b)

Fig. 16. First two mode shapes: (a) Mode 1. (b) Mode 2.

\section{Conclusions}

This work has evaluated the experimental performance of the piezoelectric resistive extension piezoelectric shunted damping (PSD) concept on a simple laboratory setup. The latter consisted of a cantilever Aluminium thin (long) beam with a single pair of same or opposite poled small piezoceramic patches bonded on its opposite faces near the clamp and wired electrically either in series or in parallel. Good correlations between theoretical and experimental optimal resistances and damping ratios were reached for the measured first two bending modes.

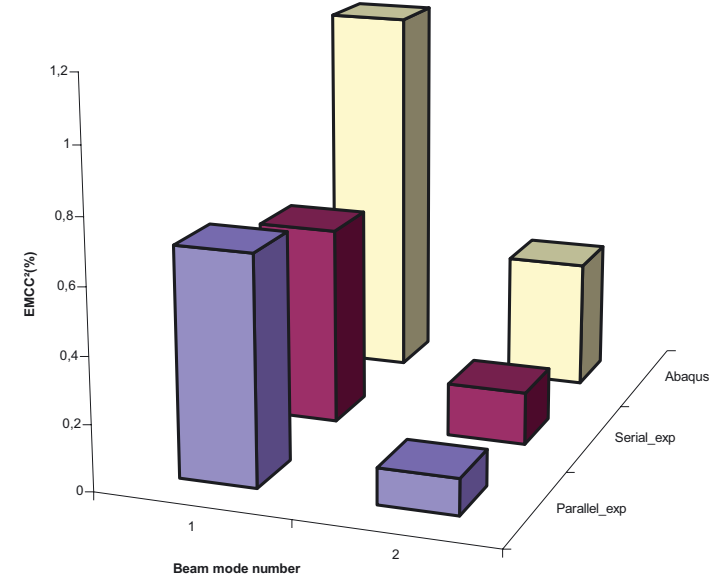

Fig. 17. Experimental and FE (with EP for OC) squared EMCC for the first two modes.

Table 4. First six FE (with EP for OC) frequencies and EMCC after electromechanical updating (EMU).

\begin{tabular}{ccccc}
\hline Configuration & \multicolumn{4}{c}{ FE (w EP) } \\
$($ EMU parameters $)$ & Mode & $f_{\mathrm{OC}}(\mathrm{Hz})$ & $f_{\mathrm{SC}}(\mathrm{Hz})$ & $K(\%)$ \\
\hline $\mathrm{SP}$ & 2 & 126.194 & 26.092 & 8.85 \\
$(k=2.05 \mathrm{MN} / \mathrm{m}$, & 3 & 333.56 & 333.56 & 0 \\
$\left.C_{\mathrm{p}}^{\mathrm{s}}=17.9 / 17.6 \mathrm{nF}\right)$ & 4 & 441.86 & 441.86 & 0 \\
& 5 & 443.99 & 443.9 & 2.02 \\
& 6 & 880.52 & 878.85 & 6.17 \\
\hline & 1 & 26.65 & 26.561 & 8.19 \\
$\mathrm{OP}$ & 2 & 161.31 & 161.24 & 2.95 \\
$k=2.48 \mathrm{MN} / \mathrm{m}$, & 3 & 343.25 & 343.25 & 0 \\
$C_{\mathrm{p}}^{\mathrm{s}}=23 / 23.8 \mathrm{nF}$ & 4 & 442.42 & 442.42 & 0 \\
& 5 & 448.2 & 448.14 & 1.64 \\
& 6 & 885.91 & 884.63 & 5.38 \\
\hline
\end{tabular}

Table 5. EMCC test/model correlation after FE models electromechanical updating (EMU).

\begin{tabular}{ccccccc}
\hline \multirow{2}{*}{ Mode } & \multicolumn{2}{c}{ Tests (ref.): } & FE w EMU: & \multicolumn{2}{c}{$\begin{array}{c}\text { Deviation } \\
K(\%)\end{array}$} & \multicolumn{2}{c}{$K(\%)$} & \multicolumn{2}{c}{$(\%)$} \\
\cline { 2 - 7 } & SP (PW) & OP (SW) & SP & OP & SP & OP \\
\hline 1 & 8.31 & 7.77 & 8.85 & 8.19 & 6.50 & 5.41 \\
2 & 3.34 & 3.96 & 2.97 & 2.95 & 11.08 & 25.5 \\
\hline
\end{tabular}

However, the obtained damping ratios were found to be very low.

On the other hand, this work has presented refined (realistic) finite element (FE) modelling and analyses using ABAQUS ${ }^{\circledR}$ commercial code of above PSD tests regarding the modal effective electromechanical coupling coefficient (EMCC) which is proposed here as a PSD performance indicator; in particular, it was found that good test/model correlations require: (i) to take care of the patches poling directions and their corresponding electric connections (wiring); (ii) to consider the equipotentiality (EP) constraint for OC electrodes; (iii) and to conduct electromechanical updating of the FE models.

This work has contributed to the PSD research field by the proposed tests and their refined simulations. It 
Table A1. Materials properties.

\begin{tabular}{cccc}
\hline Materials & Constants (SI unit) & Notations & Values \\
\hline PIC255 & Permittivity constants at constant & $\in_{11}^{\mathrm{S}}=\in_{22}^{\mathrm{S}}$ & 8.245 \\
properties as in & strain $(\mathrm{nF} / \mathrm{m})$ & $\in_{33}^{\mathrm{S}}$ & 7.122 \\
$[37])$ & Stress piezoelectric & $e_{31}=e_{32}$ & -7.25 \\
& coupling constants $\left(\mathrm{C} / \mathrm{m}^{2}\right)$ & $e_{33}$ & 14.41 \\
& & $e_{15}=e_{24}$ & 11.57 \\
& SC Young's modulii $\left(\mathrm{GN} / \mathrm{m}^{2}\right)$ & $E_{1}=E_{2}$ & 62.1 \\
& & $E_{3}$ & 48.3 \\
& SC Poisson's ratios & $\nu_{12}$ & 0.32 \\
& & $\nu_{13}=\nu_{23}$ & 0.44 \\
& SC Shear modulii $\left(\mathrm{GN} / \mathrm{m}^{2}\right)$ & $G_{12}$ & 23.5 \\
& & $G_{13}=G_{23}$ & 21 \\
Aluminum & Density $\left(\mathrm{Kg} / \mathrm{m}^{3}\right)$ & $\rho$ & 7800 \\
(assumed & Young's modulus $\left(\mathrm{GN} / \mathrm{m}^{2}\right)$ & $E$ & 69 \\
properties) & Poisson's $\mathrm{ratio}$ & $\nu$ & 0.3 \\
& Mass density $\left(\mathrm{Kg} / \mathrm{m}^{3}\right)$ & $\rho$ & 2700 \\
\hline
\end{tabular}

was discovered, from the latter, that the physical EP constraint has a decoupling effect (Fig. 13, Tab. 4) and decreases the modal effective EMCC. A recent additional experimental campaign has validated these findings [37].

Acknowledgements. This work has been supported by the European Commission via the contract $n^{\circ}$ FP6 NMP3-CT-13517 (CASSEM). The authors gratefully acknowledge this financial support.

\section{Appendix A}

The Engineering constants of the materials, used in the 3D FE simulations are shown (from [37]) in Table A1.

In $A B A Q U S^{\circledR}$ notations, these data can be put in matrix form for GUI use as follows:

- SC elastic stiffness matrix $\left[\mathbf{D}^{\varphi}\right]$

$$
\begin{gathered}
{\left[\begin{array}{cccccc}
D_{1111} & D_{1122} & D_{1133} & 0 & 0 & 0 \\
D_{1122} & D_{2222} & D_{2233} & 0 & 0 & 0 \\
D_{1133} & D_{2233} & D_{3333} & 0 & 0 & 0 \\
0 & 0 & 0 & D_{1212} & 0 & 0 \\
0 & 0 & 0 & 0 & D_{1313} & 0 \\
0 & 0 & 0 & 0 & 0 & D_{2323}
\end{array}\right]=} \\
{\left[\begin{array}{cccccc}
105.2 & 58.3 & 55.4 & 0 & 0 & 0 \\
58.3 & 105.2 & 55.4 & 0 & 0 & 0 \\
55.4 & 55.4 & 85.9 & 0 & 0 & 0 \\
0 & 0 & 0 & 23.5 & 0 & 0 \\
0 & 0 & 0 & 0 & 21.0 & 0 \\
0 & 0 & 0 & 0 & 0 & 21.0
\end{array}\right] \text { GN.m }{ }^{-2}}
\end{gathered}
$$

- Strain piezoelectric matrix [d] (converted by ABAQUS $^{\circledR}$ to the stress one $[\mathbf{e}]$ via $\left.[\mathbf{e}]=[\mathbf{d}]\left[\mathbf{D}^{\varphi}\right]\right)$

$$
\begin{aligned}
& {\left[\begin{array}{cccccc}
0 & 0 & 0 & 0 & d_{113} & 0 \\
0 & 0 & 0 & 0 & 0 & d_{223} \\
d_{311} & d_{322} & d_{333} & 0 & 0 & 0
\end{array}\right]=} \\
& {\left[\begin{array}{cccccc}
0 & 0 & 0 & 0 & 550 & 0 \\
0 & 0 & 0 & 0 & 0 & 500 \\
-180 & -180 & 400 & 0 & 0 & 0
\end{array}\right]{\mathrm{pC} . \mathrm{N}^{-1}}^{-1} }
\end{aligned}
$$

- Relative blocked dielectric permittivity (at constant strains $\varepsilon$ ) matrix $\left[\mathbf{D}^{\varepsilon}\right]$

$$
\left[\begin{array}{ccc}
D_{11}^{\varepsilon} & 0 & 0 \\
0 & D_{22}^{\varepsilon} & 0 \\
0 & 0 & D_{33}^{\varepsilon}
\end{array}\right]=\left[\begin{array}{ccc}
8.245 & 0 & 0 \\
0 & 8.245 & 0 \\
0 & 0 & 7.122
\end{array}\right] \mathrm{nF} \cdot \mathrm{m}^{-1}
$$

\section{References}

[1] R.L. Forward, Electronic damping of vibrations in optical structures, Appl. Opt. 18 (1979) 690-697

[2] IRE, IRE Standards on piezoelectric crystals: determination of the elastic, piezoelectric, and dielectric constants, Proc. IRE 46 (1958) 764-778

[3] IEEE, IEEE Standards on piezoelectricity. ANS n ${ }^{\circ} 176-$ 187, 1988

[4] M. Naillon, R.H. Coursant, F. Besnier, Analyse de structures piézoélectriques par une méthode d'éléments finis, Acta Electronica 25 (1983) 341-362

[5] S.H. Chang, N.N. Rogacheva, C.C. Chou. Analysis methods for determining electromechanical coupling coefficients of piezoelectric elements, IEEE Trans. Ultras. Freq. Control 42 (1995) 630-640 
[6] N.W. Hagood, A. von Flotow, Damping of structural vibrations with piezoelectric materials and passive electrical networks, J. Sound Vib. 146 (1991) 243-268

[7] A. Benjeddou, J.A. Ranger-Vieillard, Use of shunted shear-mode piezoceramics for structural vibration passive damping, Comput. Struct. 84 (2006) 1415-1425

[8] A. Benjeddou, J.A. Ranger, Vibration damping using resonant shunted shear-mode piezoceramics, in: C.A. Mota Soares et al. (éds.), Proceedings of the Third European Conference on Computational Mechanics, Solids, Structures and Coupled Problems in Engineering, Lisbon, June 2006

[9] B. de Marneffe, Active and passive vibration isolation and damping via shunted transducers, Thèse, Faculté des Sciences Appliquées, Université Libre de Bruxelles, Décembre 2007

[10] J.F. Deü, A. Benjeddou, Free-vibration analysis of laminated plates with embedded shear-mode piezoceramic layers, Int. J. Solids Struct. 42 (2005) 2059-2088

[11] M.A. Al-Ajmi, A. Benjeddou, Damage indication in smart structures using modal effective electromechanical coupling coefficients, Smart Mater. Struct. 17 (2008) 035023

[12] A. Benjeddou, J.A. Ranger, Simple finite element modelling and performance evaluation of passive vibration damping using shunted piezoceramics, in: Proceedings of the First International Congress on Design and Modelling of Mechanical Systems, Hammamet, March 2005

[13] G.A. Lesieutre, Vibration damping and control using shunted piezoelectric materials, Shock Vib. Dig. 30 (1998) 187-195

[14] M. Ahmadian, A.P. DeGuilio, Recent advances in the use of piezoceramics for vibration suppression, Shock Vib. Dig. 33 (2001) 15-22

[15] S.O.R. Moheimani, A survey of recent innovations in vibration damping and control using shunted piezoelectric transducers, IEEE Trans, Control Syst. Tech. 11 (2003) 482-494

[16] C. Poizat, A. Benjeddou, On analytical and finite element modelling of piezoelectric extension and shear bimorphs, Comput. Struct. 84 (2006) 1426-1437

[17] N.W. Hagood, W.H. Chung, A. von Flotow, Modelling of piezoelectric actuator dynamics for active structural control, J. Intell. Mater. Syst. Struct. 1 (1990) 327-354

[18] J.J. Hollkamp, Multimodal passive vibration suppression with piezoelectric materials and resonant shunts, J. Intell. Mater. Syst. Struct. 5 (1994) 49-57

[19] C.H. Park, Y.H. Kim, H.C. Park, Dynamic formulation of plates with shunted piezoelectric materials, J. Intell. Mater. Syst. Struct. 16 (2005) 971-976

[20] J. Kim, Y.H. Ryu, S.B. Choi, New shunting parameter tuning method for piezoelectric damping based on measured electrical impedance, Smart Mater. Struct. 9 (2000) 868-877

[21] C.L. Davis, G.A. Lesieutre, A modal strain energy approach to the prediction of resistively shunted piezoceramic damping, J. Sound Vib. 181 (1995) 129-139

[22] C. Poizat, M. Sester, Finite element modelling of passive damping with resistively shunted piezocomposites, Computational Mater. Sci. 19 (2000) 183-188
[23] K. Adashi, Y. Awakura, T. Iwatsubo, Variable hybrid piezoelectric damping based on control power requirement, in: D.J. Inman (éd.), Proceedings SPIE Smart Structures and Materials: Damping and Isolation 4331 (2001) 396-407

[24] T. Tanimoto, A new vibration damping CFRP material with interlayers of dispersed piezoelectric ceramic particles, Compos. Sci. Tech. 67 (2007) 213-221

[25] S. Desai, M. Lovell, J. Cordle, Coupled field analysis of a piezoelectric bimorph disc in a direct write process, Compos. Pt. B 38 (2007) 824-832

[26] S.B. Choi, H.S. Kim, J.S. Park, Multi-mode vibration of a CD-ROM drive base using a piezoelectric shunt circuit, J. Sound Vib. 300 (2007) 160-175

[27] G. Chevallier, J.A. Ranger, A. Benjeddou, H. Sebbah, Passive vibration damping using resistively shunted piezoceramics: an experimental performance evaluation, in: Proceedings of the Second International Congress on Design and Modelling of Mechanical Systems, Monastir, March 2007

[28] N. Zhang, I. Kirpitchenko, Modelling dynamics of a continuous structure with a piezoelectric sensor/actuator for passive structural control, J. Sound Vib. 249 (2002) 251261

[29] S.B. Kandagal, K. Venkatraman, Form factors for vibration control of beams using resistively shunted piezoceramics, Letter to the Editor of J. Sound Vib. 274 (2004) 1123-1133

[30] A. Belloli, D. Niederberger, S. Pietrzko, M. Morari, P. Ermanni, Structural vibration control via R-L shunted active fiber composites, J. Intell. Mater. Syst. Struct. 18 (2007) 275-287

[31] J. Becker, O. Fein, M. Maess, L. Gaul, Finite elementbased analysis of shunted piezoelectric structures for vibration damping, Comput. Struct. 84 (2006) 2340-2350

[32] U. Andreaus, M. Porfiri, Effect of electrical uncertainties on resonant piezoelectric shunting, J. Intell. Mater. Syst. Struct. 18 (2007) 477-485

[33] A. Agneni, F. Mastroddi, G.M. Polli, Shunted piezoelectric patches in elastic and aeroelastic vibrations, Comput. Struct. 81 (2003) 91-105

[34] M.A. Trindade, A. Benjeddou, R. Ohayon, Finite element analysis of frequency- and temperature-dependent hybrid active-passive vibration damping, Europ. J. Finite Elem. 9 (2000) 89-111

[35] M.A. Trindade, A. Benjeddou, R. Ohayon, Modelling of frequency-dependent viscoelastics for hybrid activepassive vibration control, ASME J. Vib. Acoust. 122 (2000) 169-174

[36] S. Ghorbel, G. Chevallier, A. Benjeddou, Détermination expérimentale et numérique du coefficient de couplage électromécanique généralisé de structures piézoélectriques, in : XVIème Colloque Vibrations Chocs et Bruit, Lyon, 10-12 juin 2008

[37] G. Chevallier, S. Ghorbel, A. Benjeddou, A benchmark for free vibration and effective coupling of thick piezoelectric smart structures, Smart Mater. Struct. 17 (2008) 065007, p. 11 